\title{
The Results of Endoscopic Treatment of Grade IV and V Persistent Vesiocoureteral Reflux in Children Using Polyacrylate- Polyalcohol Copolymer (Vantris)
}

\author{
Stanislaw Warchol ${ }^{1}$, Grazyna Krzemien ${ }^{2}$, Agnieszka Szmigielska², Przemyslaw Bombinski ${ }^{3}$, \\ Krzysztof Toth $^{4}$, Teresa Dudek - Warchol ${ }^{1}$ \\ ${ }^{I}$ Department of Pediatric Surgery and Urology, Medical University of Warsaw, Poland, 02-091 Warsaw, \\ Zwirki\&Wigury street 63 a \\ ${ }^{2}$ Department of Pediatrics and Nephrology, Medical University of Warsaw, Poland, 02-091 Warsaw, \\ Zwirki\&Wigury street 63 a \\ ${ }^{3}$ Department of Pediatric Radiology, Medical University of Warsaw, Poland, 02-091 Warsaw, Zwirki\&Wigury \\ street 63 a \\ ${ }^{4}$ Nuclear Medicine Laboratory Nukleomed, Warsaw, Poland, Warsaw 04-736, Zeganska street 46 a
}

*Corresponding Author: Stanislaw Warchol, 1Department of Pediatric Surgery and Urology, Medical University of Warsaw, Poland, 02-091 Warsaw, Zwirki \& Wigury street 63 a.Email: swarchol@poczta.onet.pl

\begin{abstract}
Endoscopic correction of vesicoureteral reflux (VUR) in children by subureteric injection of various tissueaugmenting substances is well accepted method of first-line interventional procedure to treat all grades of persisting reflux. However, its role in the management of high grade, i.e. grade IV and V reflux still is challenging. A limited number of reports regarding results and efficacy of endoscopic management of high grade reflux is still available. The aim of the present study was to evaluate the results of endoscopic correction of grade $I V$ and $V$ reflux in children using synthetic, non-absorbable tissue-augmenting substance polyacrylate-polyalcoholcopolymer(PPC, Vantris (®)). Over the last 5 years 61 children (31 girls, 30 boys) with 76 RRUs: (33 RRUs grade IV and 43 RRUs grade V) were treated using PPC. In all patients reflux resolved. VUR was corrected after the first PPC injection in 57 out of 76 RRUs (75\%), in 18 RRUs (23.9\%) after the second injection and in one RRU grade V after the third. The only observed complication was lateonset ureteral obstruction (9 children with 11 RRUs). Our data show that PPC injection to correct high grade reflux is very efficient option and provides a very high rate of reflux resolution after single injection.
\end{abstract}

Keywords: Vesicoureteral Reflux, Endoscopic Correction Of Reflux, Polyacrylate-Polyalcohol Copolymer, VANTRIS

Abbrevations: VUR - vesicoureteral reflux, PPC - polyacrylate-polyalcohol copolymer, PTFE polytetrafluoroethylene, Dx/HA - dextranomer/hyaluronic acid copolymer, RRU - Renal Refluxing Unit, US ultrasound scan

\section{INTRODUCTION}

Endoscopic correction of vesicoureteral reflux (VUR) in children by subureteric injection of various tissue-augmenting substances since its introduction almost 35 years ago, becomes well accepted method of first-line interventional procedure to treat all grades of persisting reflux. However, its role in the management of high grade, i.e. grade IV and V reflux still is under debate $[1,2,3,4]$. A limited number of reports regarding results and efficacy of endoscopic management of high grade reflux is still available. Various bulking agents were used for this purpose: polytetrafluoroethylene (PTFE) before 2000, dextranomer/hyaluronic acid copolymer (Dx/HA, Deflux ®) since 2000 and recently polyacrylate-polyalcoholcopolymer (PPC, Vantris ®) $[4,5,6,7,8,9,10,11,12]$. PPC (Vantris $($ ) ) a synthetic, non-absorbable tissueaugmenting substance was introduced into clinical practice in 2010 [13] and is currently used in some centers Around the world [14, 15, $16,17,18,19,20]$.The aim of the present study was to evaluate the efficacy of PPC injection to correct reflux grade IV and $\mathrm{V}$ in children. 


\section{MAterial AND Methods}

From 2012 to 2017, 134 children (81 girls, 53 boys) with total 207 renal refluxing units (RRU) grades II-V, underwent injection of PPC to treat persisting reflux. In 61 of them (31girls,30boys) was present reflux grades IV and V, comprising 76RRUs: in 33 RRUs grade IV and in 43 RRUs grade V. Primary reflux was observed in 46 out of 76 RRU, and the remaining 30 RRUs represents complex cases (reflux in boys with posterior urethral valves, in partial or complete duplication of upper urinary tract bifidus/duplex system, postoperative reflux after ureteral re-implantation because of megaureter). Table 1 and 2 presents reflux characteristic in 61 patients.

Table1. Reflux characteristic in 31 girls

\begin{tabular}{|l|l|l|l|}
\hline $\begin{array}{c}\text { VUR } \\
\text { Grade }\end{array}$ & $\begin{array}{c}\text { RRUs (no) } \\
\text { Primary } \\
\text { Reflux }\end{array}$ & $\begin{array}{c}\text { RRUs (no) } \\
\text { Complex } \\
\text { Reflux }\end{array}$ & $\begin{array}{c}\text { RRUs } \\
\text { (no) } \\
\text { Total }\end{array}$ \\
\hline IV & 13 & 7 & 20 \\
\hline V & 15 & 3 & 18 \\
\hline Total & 28 & 10 & 38 \\
\hline
\end{tabular}

Table 2. Reflux characteristic in 30 boys

\begin{tabular}{|l|l|l|l|}
\hline \multicolumn{1}{|c|}{$\begin{array}{c}\text { VUR } \\
\text { Grade }\end{array}$} & $\begin{array}{c}\text { RRUs (no) } \\
\text { Primary } \\
\text { Reflux }\end{array}$ & $\begin{array}{c}\text { RRUs (no) } \\
\text { Complex } \\
\text { Reflux }\end{array}$ & $\begin{array}{c}\text { RRUs } \\
\text { (no) } \\
\text { Total }\end{array}$ \\
\hline IV & 4 & 9 & 13 \\
\hline V & 14 & 11 & 25 \\
\hline Total & 18 & 20 & 38 \\
\hline
\end{tabular}

In all 61 children reflux was diagnosed as a result of urinary tract infection. Indications for endoscopic treatment included persistent VUR in patients with a history of previous medical treatment for at least 12 months, with the presence of renal scarring (renal scintigraphy) and with no bladder dysfunction (urodynamic study) at the time of injection.

All procedures were done during cystoscopy under general anesthesia using a pediatric operating cystoscope (Storz or Wolf). Under the ureteral orifice $0.8-1 \mathrm{ml}$ of PPC was injected using STING technique. RIN type of injection needle with laterally located injection hole ("concave side opening") was used for primary grade IV-V reflux and for complex cases, excluding reflux in bifidus/duplex system. For these cases standard needle, i.e. RINS type ("bevel tip") with injection hole at the end of the needle was applied. Figure 1 and 2 presents types of injection needles.

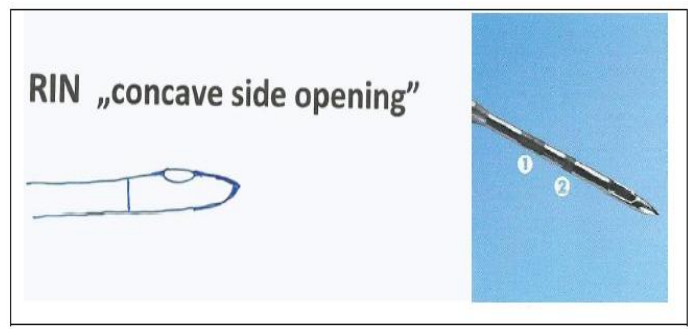

Figure1. RIN type of injection needle

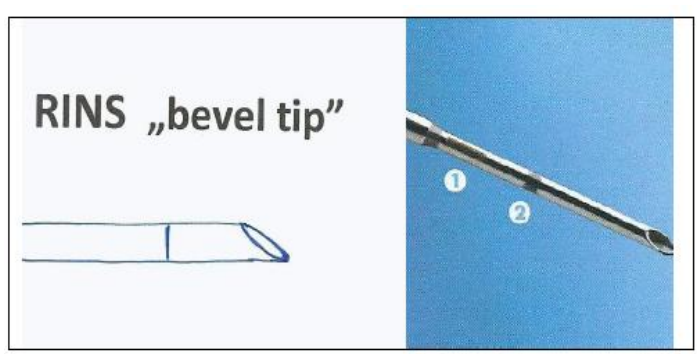

Figure2. RINS type on injection neddle

After injection of PPC apparent bulge at the site of injection was visible (Figure 3 a, b and $4 \mathrm{a}, \mathrm{b}$ ). Perioperative antibiotic prophylaxis was administered and the child was discharged home the next day after cystoscopy. Each patient underwent ultrasound scan (US) 2 weeks after injection and voiding cystourethrogram 3 months after procedure.

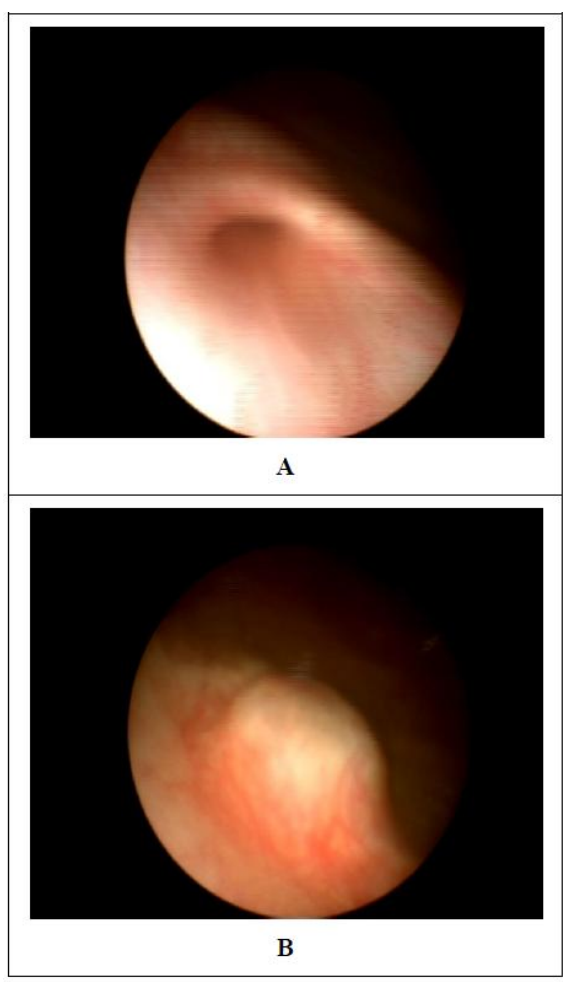

Figure 3 A, B. Ureteral orifice (reflux grade IV) before $(A)$ and after injection of PPC (B)

In case of immediate post-injection flank/abdominal pain US was performed to evaluate the degree of possible obstruction of 
the upper urinary tract. Further follow-up studies included: US scan and radionuclide examination (dynamic scintigraphy) 6 months after the procedure in each patient and then repeated US and in selected cases also radionuclide scan on individual basis.

\section{RESUlts}

The results were estimated regarding reflux resolution rate after PPC injection. All 61 children completed follow-up. In all patients reflux resolved. VUR was corrected after the first PPC injection in 57 out of 76 RRUs (75\%): 25 grade IV, 32 grade V; in 18 RRUs (23.9\%) after the second injection: 8 grade IV, 10 grade $\mathrm{V}$ and in one RRU grade $\mathrm{V}$ after the third. Table 3 present VUR resolution rate regarding reflux grade.

Table3. Reflux resolution after PPC injection

\begin{tabular}{|c|c|c|c|c|}
\hline $\begin{array}{l}\text { VUR } \\
\text { Grade }\end{array}$ & $\begin{array}{c}\text { RRUs } \\
\text { (no) }\end{array}$ & $\begin{array}{c}\text { After } \\
\text { first } \\
\text { injection } \\
\% \text { (no) }\end{array}$ & $\begin{array}{c}\text { After } \\
\text { second } \\
\text { injection } \\
\%(\text { no) }\end{array}$ & $\begin{array}{c}\text { After } \\
\text { third } \\
\text { injecti } \\
\text { on \% } \\
\text { (no) }\end{array}$ \\
\hline IV & 33 & $\begin{array}{ll}75.8 & \% \\
(25) & \end{array}$ & $\begin{array}{ll}100 & \% \\
(33) & \end{array}$ & \\
\hline V & 43 & $\begin{array}{ll}74.4 & \% \\
(32) & \end{array}$ & $\begin{array}{l}97.8 \% \\
(42)\end{array}$ & $\begin{array}{l}100 \% \\
(43)\end{array}$ \\
\hline TOTAL & 76 & $\begin{array}{ll}75 & \% \\
(57)\end{array}$ & $\begin{array}{l}98.7 \% \\
(75)\end{array}$ & $\begin{array}{l}100 \% \\
(76)\end{array}$ \\
\hline
\end{tabular}

No early ureteral obstruction was observed postoperatively. Progressive dilatation of renal collecting system and megaureter (US study) and deterioration of renal function with delayed excretion (radionuclide study) was found 0.9-2.9 years (mean $2 \pm 0.7$ ) after successful correction of VUR grades IV and V comprising $11 \mathrm{RRU}_{\mathrm{s}}$. In 7 children Politano-Lead better antireflux procedure after excision of stenotic intravesical part of ureter was performed (in 5 unilaterally, in 2 bilaterally). Two children did not show up for the planned surgery. Postoperative US and dynamic scintigraphy (mean follow-up 1 year) showed gradually decrease of dilatation of the upper urinary tract and permanent improvement of drainage and renal function.

\section{DISCUSSION}

The major drawback of endoscopic treatment for grade IV and V reflux is relatively low success rate reported. Therefore some pediatric urologists have questioned the role of endoscopic management of high grade VUR, especially grade $\mathrm{V}$ and still continue to recommend ureteral reimplantation as the treatment of choice in such cases [9].

A meta-analysis including 5527 children $(8100$ RRUs) showed resolution rate $63 \%$ for grade IV and $51 \%$ for grade V reflux as compared with $79 \%$ for grade I and II and $72 \%$ for grade III after endoscopic injection of Dx/HA (Deflux (B). The authors of this report concluded that endoscopic treatment provide a high rate of success with Dx/HA, which decreases with increasing grade of VUR and therefore multiple injections may be necessary [1]. Similar findings regarding success rate with $\mathrm{Dx} / \mathrm{HA}$ (Deflux $(\circledR)$ were noted in review of 47 studies published in 2010 [2].

Since 2003 there were published few reports presenting the results of endoscopic correction of exclusively grade IV or $\mathrm{V}$ reflux, mainly primary VUR, using PTFE and Dx/HA (Deflux $(\circledR)$. The presented success rates were similar to that from meta-analysis reports. Chertin et al in 2003 presenting the results with PTFE for endoscopic correction of primary grades IV and V VUR (526 children, 917 RRUs) reported 58\% success rate after single injection and $84 \%$ after second and third [5]. In 2007 Menezes and Puri reviewed 21 year experience of endoscopic treatment of primary VUR grade $\mathrm{V}$ in 132 children (166 RRUs) with PTFE and Dx/HA (Deflux $®$ ). Reflux completely resolved after first injection in 53\% of ureters and downgraded to grade I or II in $15.7 \%$. After second procedure VUR resolved in $21.7 \%$ and after third in $3.6 \%$ of ureters [8]. The same results were described in the other papers [6,7]. In 2010 Hunziker et al presenting 8-years experience with endoscopic correction of primary grade $\mathrm{V}$ reflux using Dx/HA (Deflux ®) (56 children, 63 RRUs) noted $52.4 \%$ success rate after single injection and downgrading to grade I in $11.1 \%$ whereas $30.2 \%$ of ureters required second and $6.3 \%$ third injection to resolve VUR [9]. Recently published results with PPC (Vantris (B) to treat grade IV and V VUR showed significantly higher success rate as compared with Dx/HA (Deflux $®$ ): 80-83,3\% resolution rate after single injection $[10,11]$ or even $91.8 \%$ [12]. In 2013 we published our preliminary results: 13 RRUs grade IV VUR and 19 RRUs grade $\mathrm{V}$ with reflux resolution rate in $84.6 \%$ and $89.5 \%$ of RRUs respectively after first injection and in $100 \%$ after repeated procedure [18]. 
Our results with the use of PPC (Vantris ${ }^{\circledR}$ ) to treat grade IV and V VUR in 61 children with 76 this RRUs, including, primary reflux as well as complex cases, confirm that this syntetic and non-absorbable bulking substance is very effective for the endoscopic management of high grade reflux regarding reflux resolution rate. In all children VUR resolved after PPC injection: in $76 \%$ of RRUs after first, and in 98.7 after second treatment. Only in one case with reflux grade $\mathrm{V}$ (reflux in a boy with posterior urethral valves) 3 injections were necessary to achieve success.

Postoperative obstruction after endoscopic treatment of VUR using bulking substances is well known reported phenomenon [21, 22]. Acute and delayed ureteral obstruction is also described after Vantris ${ }^{\circledR}$ injection and is estimated as the main postoperative complication. Early obstruction is managed expectantly, late is treated with insertion of the double $\mathbf{J}$ stent or requires open ureteroneocystostomy [10, 13, 15, 20, 23,24].

In our experience the only significant and serious complication encountered with PPC using to correct grade IV and V reflux was late ureteral obstruction, requiring ureteral reimplantation in all cases.

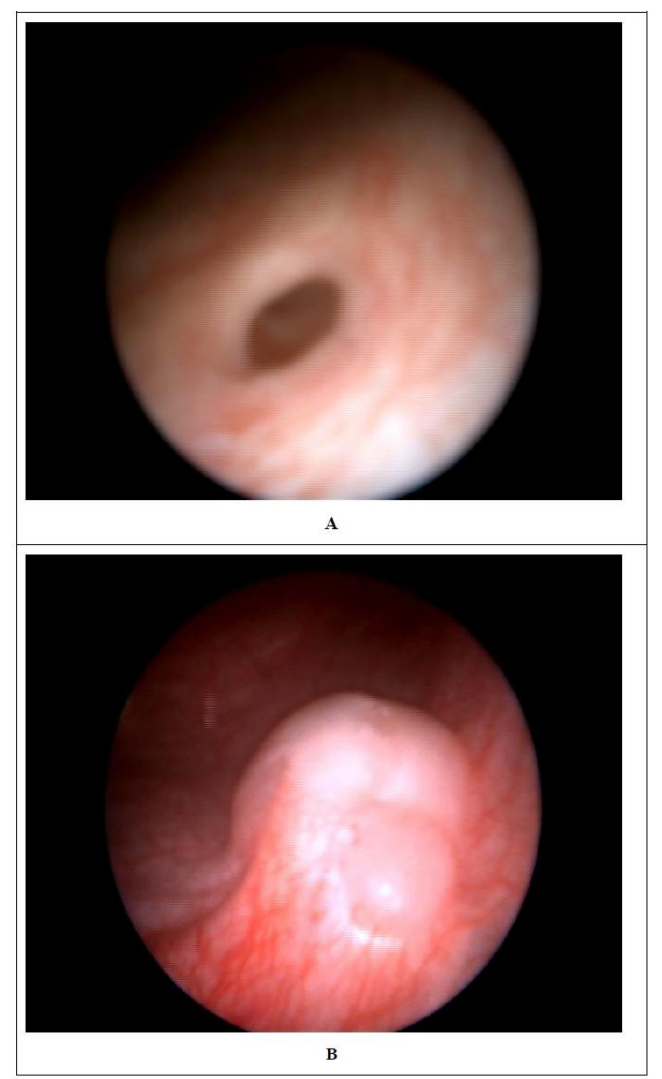

Figure 4 a, b. Ureteral orifice (reflux grade $V$ ) before (a) and after PPC injection (b).

\section{Conclusions}

Our data show that PPC injection to correct high grade reflux (IV and V grade) is very efficient option and provides a high rate of reflux resolution after single injection. This observation confirms the previously published data that endoscopic management should be first line option to treat persisting high grade reflux. However, further studies with more patients and longer follow-up periods are needed to draw final conclusions.

\section{REFERENCES}

[1] Elder JS, Diaz M, Caldamone AA, Cendron M, Greenfiled S, Hurwitz R, Kirsch A, Koyle MA, Pope J, Shapiro E. Endoscopic therapy for vesicoureteral reflux: a meta-analysis. I. Reflux resolution and urinary tract infection. J Urol. 2006; 175: 716-722.

[2] Routh JC, Inman BA, Reinberg Y. Dextranomer/hyaluronic acid for pediatric vesicoureteral reflux: systematic review. Pediatrics. 2010; 125: 1010-1019.

[3] Chertin B, Kocherov S. Long-term results of endoscopic treatment of vesicoureteral reflux with different tissue-augmenting substances. J Pediatr Urol. 2010; 6: 251-256.

[4] Puri P, Kutasy B, Colhoun E Hunziker M. Single center experience with endoscopic ubureteraldextranomer/hyaluronic acid injection as first line treatment in 1,551 children with intermediate and high grade vesicoureteral reflux. J Urol. 2012;188: (4 Suppl): 1485-1489.

[5] Chertin B, De Caluwe D, Puri P. Endoscopic treatment of primary grades IV and $\mathrm{V}$ vesicouretyeral reflux in children with subureteral injection of polytetrafluoroethylene. J Urol. 2003; 169: 1847-1949.

[6] Puri P, Priker M, Mohanan N, Dawrant M, Dass L, Colhoun E. Subureteral dextranomer/hyaluronic acid injection as first line treatment of high grade vesicoureteral reflux. J Urol. 2006; 176 (4Pt2): 1856-1859.

[7] Dawrant MJ, Mohanan N, Puri P. Endoscopic treatment for high grade vesicoureteral reflux in infants J Urol.2006; 176 (4PT2): 1847-1850.

[8] Menezes MN, Puri P. The role of endoscopic treatment in the management of grade $\mathrm{V}$ primary vesicoureteral reflux. Eur Urol. 2007; 52: $1505-1510$.

[9] Hunziker M, Mohanan N, D’Asta F, Puri P. Endoscopic treatment of primary grade vesicoureteral reflux using hyaluronic acid 
copolymer (DX/HA). Pediatr Surg Int. 2010; 26: 977-979.

[10] De Badiola FI, Soria R, Vagni RL, Ormaechea MN, Moldes JM, Benamor C. Results of treatment of grades IV and $\mathrm{V}$ vesicoureteral reflux with endoscopic injection of polyacrylate polyalcoholcopolymer. Front Pediatr.2013;1:32.doi:10.3389/fped.2013.00032.

[11] Kocaoglu C. Endoscopic treatment of grades IV and $\mathrm{V}$ vesicoureteral reflux with two bulking substances: dextranomer hyaluronic acid copolymer versus polyacrylate polyalcoholcopolymer in children. J Pediatr Surg.2016; 51:1711-1715.

[12] Asgari SA, Asl AS, Safarinejad MR, Ghanaei MM. High success rate with new modified endoscopic treatment for high-grade VUR: a pilot study with preliminary report. J Pediatr Urol.2016; 12: 100.e1-4.

[13] Ormaechea M, Ruiz E, Denes E, Gimenez F, Denes FT, Moldes J, Amarante A, Pioner G, Dekermacher S, de Badiola F. New tissue bulking agent (polyacrylate polyalcohol) for treating vesicoureteral reflux: preliminary results in children. J Urol. 2010;183: 714-717.

[14] Chertin B, Arafeh WA, Zeldin A, Ostrovsky IA, Kocherov S. Endoscopic correctionof VUR using vantris as a new non-biodegrable tissue augmenting substance: three years of prospective follow-up. Urology. 2013; 82:201204.

[15] Kocherov S, Ulman I, Nikolaev S, Corbetta JP, Rudin Y, Slavkovic A, Dokumcu Z, Avanoglu A, Menovshchikova L, KOvarsiy S, Skliarova T, Weller S, Bortagaray JI, Lopez JC, Duran V, Burek C, Sager C, Maruhnenko D, Garmanova T, Djamal A, JovanovicZ,Vacic N, Abu Arafeh W, Chertin B. Multicenter survey of endoscopic treatment of vesicoureteral reflux using polyacrylate-polyalcohol bulking copolymer (Vantris).Urology.2014;84:689-693.

[16] Corbetta JP, Bortagaray JI, Weller S, Ruiy J, Burek C, Sager C, Duran V, Lopez JC. The use of polyacrylate-polyalcohol copolymer hydrogel in the endoscopic treatment of primary vesicoureteral reflux in children. J Pediatr Surg. 2015; 50: 485-488.

[17] Karakus SC, User IR, Kilic BD, Akacer V, Ceylan H, Ozokutan BH. The comparison of dextranomer/hyaluronic acid and polyacrylate- polyalcohol copolymers in endoscopic treatment of vesicoureteral reflux. J Pediatr Surg.2016; 51: 1496-1500.

[18] Warchol S, Krzemien G, Szmigielska A, Bombinski P, BrzewskiM,Dudek-Warchol T. Comparison of results of endoscopic correction of vesicoureteral reflux in children using two bulking substances: dextranomer/hyaluronic acid copolymer (Deflux) versus polyacrylatepolyalcohol copolymer (Vantris).J Pediatr Urol. 2016; 12: 256.e1-4.

[19] Taskinlar H, Avlan D, Bahadir GB, Delibas A, NayciAThe outcomes of two different bulking agents (dextranomer/hyaluronicacid copolymer and polyacrylate polyalcohol copolymer) in the treatment of primary vesico-ureteral reflux. Int Braz J Urol. 2016; 42: 514-520.

[20] Warchol S, Krzemien G, Szmigielska A, Bombinski P, TothK,Dudek-Warchol T. Endoscopic correction of vesicoureteral refluxing children using polyacrylatepolyalcohol copolymer (Vantris): 5-years of prospective follow-up. Cent European J Urol. 2017; 70: 314-319.

[21] Mazzone L, Gobet R, Gonzales R, Zweifel N, Weber DM. Ureteral obstruction following injection of dextranomer/hyalutronic acid copolymer: an infrequent but revelant complication. J Pediatr Urol. 2012;8:514-519.

[22] Garcia-Aparicio L, Rodo , Palazon P, Martin O.,Blazquez-Gomez E, Manzanaraes A, Garcia-Smith N, Bejarano M, de Haro I, Ribo JM. Acute and delayed vesicoureteral obstruction after endoscopic treatment of primary vesicoureteral reflux with dextranomer/hyalutronic acid copolymer: why and how to manage. J Pediatr Urol. 2013;9:493497.

[23] Alizadeh F, Mazdak H, Khorrami MH, Khalighinejad P, Shoureshi P. Postoperative ureteral obstruction after endoscopic treatment of vesicoureteral reflux with polyacrylate polyalcohol copolymer (Vantris®). J Pediatr Urol. 2013;9:488-492.

[24] Şencan A, Yildirim H, Özkan KU, Ucan B, Evciler H, Karkiner A, Hoşgör M. Late ureteral obstruction after endoscopic treatment of vesicoureteral reflux with polyacrylate polyalcohol copolymer. Urology. 2014; 84:1188-1193.

Citation: Stanislaw Warchol, Grazyna Krzemien, Agnieszka Szmigielska, Przemyslaw Bombinski, Krzysztof Toth \& Teresa Dudek - Warchol. The Results of Endoscopic Treatment of Grade IV and V Persistent Vesiocoureteral Reflux in Children Using Polyacrylate-Polyalcohol Copolymer (Vantris). ARC Journal of Urology. 2017; 2(4):12-16. doi: dx.doi.org/10.20431/2456-060X.0204003.

Copyright: ( 92017 Authors. This is an open-access article distributed under the terms of the Creative Commons Attribution License, which permits unrestricted use, distribution, and reproduction in any medium, provided the original author and source are credited. 